\title{
RELEVÂNCIA E MOTIVAÇÃO: PROPRIEDADES INERENTES DA AQUISIÇÃO DE LÍNGUAS ADICIONAIS
}

\author{
Marina Xavier Ferreira ${ }^{1}$
}

\begin{abstract}
RESUMO: Muitas pesquisas têm surgido na Pragmática social e cognitiva, e os estudos linguísticos tomaram um novo caminho. Esta nova perspectiva também aparece nos estudos de aquisição de línguas adicionais, com novas concepções de aprendizagem e elementos importantes para a aquisição de uma língua. Dentre eles está a motivação, que acreditamos ser um elemento crucial para a aquisição de línguas, bem como a relevância, propriedade cognitiva proposta por Sperber e Wilson (1986), que determina o processamento cognitivo em níveis de efeito e esforço. Nosso objetivo é identificar a relação entre as propriedades cognitivas relevância e motivação e determinar como essa relação influencia no processo de aquisição de línguas adicionais. Para tanto, utilizamos como aporte teórico para esta pesquisa principalmente os estudos de Sperber e Wilson (2001,2005), Ryan e Deci (2000), Schwartz (2014), Tapia (2005, 2015), Kreitler (2013), entre outros. Pudemos perceber que a motivação e a relevância são propriedades cognitivas muito importantes para a aquisição de línguas adicionais, que são elementos correspondentes e dependentes dos mesmos fatores cognitivos e sociais.
\end{abstract}

PALAVRAS-CHAVE: Relevância; Motivação; Aquisição de línguas adicionais; Pragmática.

ABSTRACT: Much research has emerged in social and cognitive pragmatics, and linguistic studies have taken a new path. This new perspective also appears in studies of acquisition of additional languages, with new conceptions of learning and important elements for the acquisition of a language. Among them is motivation, which we believe to be a crucial element for language acquisition, as well as relevance, the cognitive property proposed by Sperber and Wilson (1986), which determines cognitive processing at levels of effect and effort. Our goal is to identify the relationship between cognitive properties, relevance and motivation and to determine how this relationship influences the process of acquiring additional languages. For that, we used as a theoretical contribution for this research mainly the studies of Sperber and Wilson (2001,2005), Ryan and Deci (2000), Schwartz (2014), Tapia

\footnotetext{
${ }^{1}$ Doutoranda em estudos Linguísticos no programa de Pós Graduação em Letras da Universidade Federal do Paraná (UFPR). Professora colaboradora no Departamento de Estudos da Linguagem da Universidade Estadual do Paraná (UEPG), Ponta Grossa, Paraná, Brasil. E-mail: marina.xavieruepg@hotmail.com.
} 
(2005, 2015), Kreitler (2013), among others. We could see that motivation and relevance are very important cognitive properties for the acquisition of additional languages, which are corresponding elements and dependent on the same cognitive and social factors.

KEY-WORDS: Relevance; Motivation; Acquisition of additional languages; Pragmatic.

\section{Introdução}

Nas últimas décadas os estudos linguísticos avançaram no que diz respeito aos estudos da linguagem, em especial a Pragmática, que cresceu significativamente e contribuiu para pesquisas de diferentes temáticas. Temos evidenciado este crescimento como um sinal de que os linguistas têm finalmente se preocupado em pesquisar as questões referentes ao uso da linguagem e como elas podem interferir significativamente nas questões sociais da comunicação. Isso se dá também no processo de ensino-aprendizagem de línguas, que acreditamos ser tanto cognitivo como social. Um dos temas mais observados neste processo é a motivação. A motivação tem sido estudada por diversas vertentes teóricas, sendo a primeira delas a Psicologia. Após os estudos da Psicologia, outros pesquisadores de diferentes áreas começaram a verificar a importância da motivação nas distintas ações do ser humano. Uma das vertentes que também têm utilizado a motivação em suas pesquisas é a aquisição de línguas adicionais.

Nesta perspectiva, acreditamos que os estudos pragmáticos podem nos ajudar a identificar as relações sociais e cognitivas da aquisição de línguas adicionais, pois esta tem como base a comunicação a partir de uma língua adicional à que o indivíduo já possui, a língua materna. Neste caso, consideramos que a interface entre os estudos do uso da linguagem e a motivação na aquisição de línguas adicionais também pode ser um tema interessante para a Pragmática, tanto em seus aspectos cognitivos como sociais. Desta forma, este trabalho visa um aprimoramento nos estudos da comunicação, mais especificamente nos estudos linguísticos. 
Assim, fundamentados na pesquisa de Sperber e Wilson (a Teoria da Relevância, de 1986) propomos um estudo que contemple os aspectos pragmáticos da comunicação em relação à motivação na aquisição de línguas adicionais. Para a formulação deste trabalho, temos como pressuposto algumas premissas. São elas: a) a relevância é uma propriedade cognitiva da comunicação que auxilia no processamento cognitivo de entrada dados. Acreditamos que na comunicação o processo de aquisição de línguas adicionais também seja influenciado por essa propriedade; b) a motivação é uma propriedade dos seres humanos que impulsiona as ações dos humanos. Consideramos que a motivação ajuda na aquisição de línguas, como já foi exposto por diversos autores.

Se assim o for, podemos formular nossa hipótese: relevância e motivação são propriedades mentais que influenciam diretamente na aquisição de línguas adicionais. Nosso texto, portanto, é de cunho bibliográfico, mas com algumas conclusões significativas para este tema.

\section{A interface motivação e relevância como propriedades da aquisição de línguas adicionais.}

A relevância é uma propriedade cognitiva postulada por Sperber e Wilson em 1986, que considera que os seres humanos somente dão atenção e processam inferencialmente o que lhes é relevante, ou seja, o que lhes dá um sentido, um efeito contextual, um melhoramento em seu ambiente cognitivo. A partir deste pressuposto e dos princípios regidos pela Teoria da Relevância, podemos afirmar que a relevância é a principal propriedade cognitiva que rege o processamento inferencial, pois apenas prestamos atenção e processamos algo que nos é relevante e que nos causa um efeito contextual considerável. Se assim o for, de acordo com a TR, o ser humano processa apenas as informações que estejam de acordo com seu princípio natural: a mente conseguir um maior efeito cognitivo com um menor esforço de processamento. Desta 
forma, segundo Sperber e Wilson (2001, 2005), o estímulo mais relevante será aquele que atingir maior efeito com um menor esforço.

Ao abordarmos o ensino-aprendizagem de línguas a partir dos conceitos da TR, podemos constatar que o professor, ao se comunicar em sala de aula, produz enunciados que serão mais ou menos relevantes aos alunos. Os estudantes, por sua vez, receberão os inputs linguísticos produzidos pelo professor $^{2}$, sendo estes inputs encaminhados a áreas específicas do cérebro e na mente transformados em sinais/pulsos elétricos e posteriormente decodificados em fórmulas lógicas (linguagem mental) para que possam ser processados mentalmente. Se a informação for nova, após a entrada e sua decodificação, o input demandará (ou não) uma expectativa provável de relevância, em que constatará se a informação nova será suficientemente relevante a ponto de ser processada, ou seja, se há uma possibilidade de causar efeitos contextuais altos para que valha a pena o esforço mental gasto no processamento. Desta forma, ao ser processado, o input gerará um dado efeito e será esse efeito que conduzirá a mente à otimização da relevância e ao reajuste de informações antigas por meio do novo conhecimento, remodelando e aperfeiçoando o ambiente cognitivo do aluno.

Entretanto, é tácito que nem sempre os enunciados emitidos pelo professor são percebidos como relevantes pelos alunos. Além disso, o processo de ensinoaprendizagem não é um processo que causa um grande efeito contextual ao estudante com pouco esforço de processamento. Ao contrário, no ambiente escolar o processamento de informações novas tende a ser efetuado com um grande esforço, principalmente se não existe uma expectativa possível de relevância no início deste processamento. E é neste ponto que encontramos um problema: se o aluno irá processar apenas o que lhe é relevante e que lhe gere um grande efeito contextual com um baixo esforço de processamento, como ocorrerá o ensino-aprendizagem se muitas vezes o que o professor ensina não lhe é relevante e o esforço de processamento é alto?

\footnotetext{
${ }^{2}$ Não desconsideramos os demais inputs produzidos pelo professor na sala de aula, pois sabemos que o contexto de aprendizagem é variável, portanto, sabemos que outros inputs são produzidos, como o input visual, por exemplo. No entanto, consideramos o input linguístico como o mais importante para a comunicação, bem como para a aprendizagem.
} 
Então o aluno nunca aprenderá nada do que o professor o tenta ensinar, nem processará os inputs produzidos pelos docentes?

É difícil responder às perguntas, pois sabemos que os alunos sempre aprendem alguma coisa do que o professor tenta ensinar, uns mais, outros menos, e a aquisição do conteúdo acontece, mesmo existindo esse "filtro cognitivo", que é a relevância (e sua expectativa provável). Então, o que faz o aluno adquirir conhecimento, mesmo efetuando um grande esforço cognitivo para aprender o conteúdo? Esta pergunta nos remete a questões que não vão ao encontro dos princípios da TR, pois, para Sperber e Wilson (2001), processamos apenas o que nos é relevante e que nos cause um efeito elevado com um esforço mental reduzido.

Uma hipótese seria o professor auxiliar o processo de aprendizagem, tornando o conteúdo mais relevante ao aluno, trazendo as novas informações de forma que elas se encaixem no conhecimento do aluno e façam sentido para ele. A partir do momento em que o aprendiz perceba que o conteúdo estudado pode ter algum significado ou utilidade para sua vida, provavelmente aquele conhecimento será mais relevante e seu aprendizado será mais eficaz. Por mais que o aluno muitas vezes não atribua relevância de forma ativa a todos os inputs, acreditamos que em algum momento ele irá determinar alguma relevância em alguns momentos da aula, de acordo com suas necessidades sociais.

No entanto, como o professor pode fazer com que o esforço cognitivo do aluno ao processar as informações novas seja menor, para que este alcance um efeito cognitivo maior? Acreditamos que o esforço depreendido sempre será grande, pois o processo de ensino-aprendizagem geralmente é custoso em termos de esforço cognitivo, mas existe algo que faz com que valha a pena para o aluno realizar esse esforço e seu efeito seja elevado da mesma forma. A hipótese que nos parece adequada é que, se o aluno estiver motivado, o esforço de processamento poderá ser compensado, pois o nível de efeitos contextuais aumentará.

Em consonância com as concepções de Sperber e Wilson (2001), Kruglanski e Sheveland (2013) defendem que o novo conhecimento é uma conclusão baseada em evidências e essas conclusões do processamento são derivadas do conhecimento no modelo dedutivo. Assim, os novos conhecimentos surgem pela mediação das regras 
inferenciais, que realizam a confirmação de fatos. Essa confirmação de fatos é constituída de premissas menores, os conhecimentos enciclopédicos. Assim, o novo conhecimento vem de blocos cognitivos construídos por meio dos conhecimentos anteriores. Segundo os autores, tudo isso requer tempo e esforço, e é aqui que o elemento motivacional se torna importante, pois, a pesar do esforço e tempo depreendidos, se o indivíduo estiver motivado o processo de aquisição dos novos conhecimentos ocorrerá de forma satisfatória.

Desta maneira, podemos inferir que algumas vezes a aquisição de novos conhecimentos não vai ao encontro das expectativas cognitivas naturais do ser humano, que são regidas pelo Princípio de Relevância - maior efeito para um menor esforço. Logo, a motivação do aluno é uma propriedade psicológica essencial para que ocorra a aquisição, pois à medida que existe algum grau de motivação no aluno poderá haver uma expectativa inicial de relevância, assim como o efeito contextual poderá ser elevado. Consideramos esta hipótese verossímil aos conceitos por nós elencados e à proposta deste texto.

Segundo Schwartz (2014), um aluno está motivado quando o que ele faz tem algum significado. Considerando que o sentido de um conceito tem sua relação semântica atrelada ao estado de mundo e o significado tem sua relação atrelada ao indivíduo e seus conhecimentos, podemos deduzir que quando algo tem significado para alguém é porque foi contextualizado mentalmente (SPERBER; WILSON, 2001). Então, o significado tem relação com os conhecimentos individuais e com o contexto. Para Schwartz, no caso da sala de aula, essa contextualização ocorre no ambiente social, pois o conteúdo em questão tem que ter relação com o conteúdo já aprendido pelo aluno. Além disso, o contexto situacional da sala de aula influencia muito na motivação, pois, as situações sociais em que o aluno está inserido têm relação íntima com o contexto cognitivo dos mesmos, suas emoções, crenças e afetividades, sendo estas influenciadoras no processamento dos inputs. Ou seja, se o estudante não se sentir bem na sala de aula ou na escola, sua motivação poderá diminuir, bem como seu desempenho escolar. Em consequência, ele não conseguirá visualizar alguma relevância nos conteúdos propostos, nem no próprio processo de aprendizagem. 
Por conseguinte, o contexto não é apenas um componente situacional e temporal, mas é também um componente cognitivo que funciona como um pano de fundo no processo inferencial. À medida que o contexto situacional e o contexto cognitivo mudam, a motivação também mudará. Como foi explicado, o contexto é dinâmico e sempre muda a cada novo input processado. A motivação, por sua vez, também é mutável, o que faz dela uma propriedade dinâmica, como defende Schwartz (2014). Ou seja, a motivação nunca é estática, mas sempre está em constante mudança, numa relação de graus, dependentes do contexto. Desta forma, o significado se dá quando o input é contextualizado mentalmente, por intermédio da relevância. Portanto, como apontam Sperber e Wilson (2001), quando um input é relevante ele terá um significado para o indivíduo.

Assim sendo, como Schwartz (2014) sustenta, a motivação deve ser retroalimentada, pois ela sempre estará sujeita a estar mais elevada ou reduzida. Como o contexto é dinâmico e a motivação sempre depende do contexto, esta necessita sempre ser retroalimentada para manter-se em graus elevados. Ryan e Deci (2000) classificam a motivação em três principais tipos, a extrínseca, a intrínseca e a amotivação. Logo, se o aluno está neste momento extrinsecamente motivado, pode ser que num momento seguinte ele passe a estar intrinsecamente motivado. Esta elevação da motivação pode ser causada por intermédio de algum efeito cognitivo produzido por algum input novo, seja este input um conteúdo interessante trabalhado pelo professor, seja por um ato ostensivo do professor (o docente pode ter dito algo ao aluno que demonstre que este vai bem nas aulas e tem um bom conhecimento ou que o aluno está melhorando em uma disciplina que tinha dificuldades, etc.), ou por alguma identificação afetiva/emotiva com algo na aula ou no espaço escolar (passar a ter uma relação de amizade com o professor, ter um relacionamento melhor com seus colegas de classe, etc.). Da mesma forma, um aluno intrinsecamente motivado pode passar a estar extrinsecamente motivado na aula por qualquer coisa que o desmotive. Esta desmotivação pode ser causada por um determinado conteúdo que não tem sentido e/ou significado para o aluno, por um exercício que não lhe interesse, por ter uma relação ruim com o professor ou com os colegas ou até mesmo por questões pessoais que não estejam diretamente ligadas ao contexto escolar. Por fim, um aluno amotivado 
pode, por qualquer um dos motivos elencados, passar a estar motivado extrinsecamente ou, ao contrário, um aluno com uma motivação extrínseca pode se desmotivar tanto que passe ao estado de amotivação.

É importante ressaltar que não há como motivar alguém diretamente, seja por intermédio do professor, do conteúdo ou dos colegas, pois a motivação já está presente no ser humano, sendo apenas possível realizar ações ou atividades que possam auxiliar no grau de motivação do aluno (SCHWARTZ, 2014).

Em uma perspectiva diferente da de Ryan e Deci (2000) Schwartz (2014) defende que não há como o ser humano estar desmotivado. Ela explica que há muita confusão na literatura quanto aos termos desmotivação e amotivação. O ser humano nunca está totalmente desmotivado, mas, sim, pode apresentar um estado temporário de desmotivação ou amotivação quanto a um input, mas não a tudo que está em contato. Chamamos de estado (em contraste com o significado linguístico do verbo ser) porque não há uma permanência nesta falta de interesse: ela pode manter-se por um tempo, ou mudar gradativamente, como dissemos acima. Autores como Dörnyei (2010), Gardner (1999) e Deci e Ryan (2000) defendem que a motivação ocorre em graus, mas falam da falta de motivação como uma ausência desta em sua totalidade, o que, em tese, acreditamos que não ocorre. Por esse motivo afirmamos que não há como motivar ou desmotivar alguém: nós apenas conseguimos ostensivamente "direcionar" os inputs para que estes tenham um maior ou menor grau de motivação, e por conseguinte, maior relevância.

Segundo Tapia (1997) e Schwartz (2014), cada indivíduo possui metas e expectativas diferentes, que variam de acordo com suas idiossincrasias. A TR também descreve a relação dos indivíduos e suas idiossincrasias, de modo que o contexto é dependente desta relação e por meio dela e dos conhecimentos enciclopédicos é que se dá a expectativa inicial de relevância para o provável processamento de um input. Assim, da mesma forma que cada um irá processar os inputs de maneiras diferentes, cada indivíduo também terá graus de motivação diferentes em um mesmo contexto situacional. Schwartz (2014) afirma que o comportamento motivado é desencadeado através da interação entre as características subjetivas dos indivíduos e o contexto específico. Essa relação também está presente na TR, pois o contexto mental é formado 
pelas características individuais do ouvinte e é este contexto que determinará o grau de relevância do input. Em efeito, no nosso caso, o professor nunca conseguirá manter o grau de motivação de todos os alunos da mesma forma, ou seja, elevado, e nem o nível de relevância será o mesmo para todos os aprendizes, uma vez que, tanto a motivação como a relevância são características individuais.

Outro aspecto em que a motivação e a relevância se equiparam é a relação custo-benefício de efeito e esforço. Para a TR, algo nos é relevante se produz um efeito cognitivo grande para um esforço pequeno. Segundo Schwartz (2014) a motivação para aprender algo tem um custo de tempo e esforço. A autora ainda afirma que a motivação se manifesta quando há esforço. Em consonância, o efeito contextual proposto pela TR pode ser relacionado com o efeito final proposto por Schwartz (2014). Logo, podemos afirmar que este efeito retroalimenta a motivação e a relevância, pois quando um aluno aprende algo e aquilo lhe traz prazer, ele continua com um alto grau de motivação, ao mesmo tempo em que a expectativa inicial de relevância é confirmada. Por conseguinte, se o aluno não entender algum ponto na aula, se o tema da aula não for interessante para ele, ou qualquer outra coisa acontecer que não seja mais relevante prestar atenção no que está acontecendo na aula, seu grau de motivação cairá, bem como seu desempenho escolar/acadêmico.

Tapia e Fita (2015) e Schwartz (2014) ressaltam que a motivação pode diminuir por fatores externos ao indivíduo, como também por condições físicas, sociais, psicológicas, emocionais, crenças, valores e conhecimentos. Os fatores elencados pelos autores também contribuem para relevância, determinando-a por meio do contexto.

Ademais, Tapia e Fita (2015) e Schwartz (2014) afirmam que uma das características importantes para a motivação é o conhecimento prévio do aluno, chamado pela TR de conhecimento enciclopédico. Para os pesquisadores, a motivação produz uma energia que suscitará as ações comportamentais, as quais são selecionadas com base no conhecimento prévio. Em consonância, a TR propõe que um input será processado e contextualizado quando o conhecimento novo for coadunado com os conhecimentos enciclopédicos, remodelando desta forma o ambiente cognitivo do indivíduo. Esses conhecimentos enciclopédicos fazem parte de todo o arcabouço 
cognitivo que o indivíduo tem acessível em sua mente, seus conhecimentos empíricos e experiências de vida.

Destarte, de acordo com Tapia e Fita (2015) e Schwartz (2014), a motivação em sala de aula se dá na interação do contexto com as individualidades dos alunos. As individualidades que os autores elencam são as afetividades e os conhecimentos prévios. Segundo Sperber e Wilson (2001), a interação das idiossincrasias e do conhecimento enciclopédico se dão no contexto. Para a TR, o contexto é um pano de fundo dependente das idiossincrasias do indivíduo e de seus conhecimentos enciclopédicos e esse pano de fundo contextual estará presente durante o processo inferencial, podendo ser aperfeiçoado com a junção de outros contextos disponíveis. Como dito anteriormente, a interação contextual proposta por Tapia e Fita (2015) e Schwartz (2014) é a relação de sala de aula, mas, como vimos, na concepção da TR, a interação contextual vai além da sala de aula, o que faz da interação entre contexto e idiossincrasias uma relação mutável e gradativa de acordo com o tempo, espaço e com os inputs comunicativos que forem processados e coadunados nesta interação.

Portanto, a motivação e a relevância são propriedades mentais imprescindíveis para a aquisição de conhecimento. As duas são dependentes do contexto (mental e situacional), das individualidades dos alunos (crenças, valores, emoções e afetividades), bem como da relação efeito e esforço, no que se refere ao processamento de informações. Entretanto, podemos afirmar que, enquanto a motivação impulsiona e determina uma ação, a relevância determina o processo inferencial e seus efeitos e esforços.

\section{A motivação na perspectiva mental.}

Kreitler, no capítulo "The structure and dynamics of cognitive orientation: a motivational approach to cognition" do livro Cognition e Motivation (2013), afirma que a mente é formada por diversos elementos, dentre eles a cognição, as emoções e a motivação. Nesta concepção, a motivação deixa de ser algo psicológico ou social, e passa a ser uma propriedade mental do indivíduo. Para Kruglanski e Sheveland (2013) a formação do conhecimento contém os dois maiores elementos da mente: a cognição 
e a motivação. Kreitler (2013) defende que a motivação é um fator importante que afeta os conteúdos e processos da cognição. Além disso, a autora pressupõe que a cognição é um importante componente da motivação. Isso se dá quando falamos em atos cognitivos.

Kreitler (2013) explica que um ato cognitivo é formado por conteúdos cognitivos e processos cognitivos. Assim, os processos são os diferentes tipos de inferências e processos computacionais que todo ser humano pode realizar mentalmente na entrada de dados (input) ou evocações. Estes processos fazem parte do sistema dedutivo descrito pela TR. Desta forma, segundo Kreitler, os processos fazem parte da cognição, mas não são influenciados pelas emoções ou pela motivação. O conteúdo diz respeito aos conceitos que temos na mente, que estão armazenados em nossa memória enciclopédica. Quando o conteúdo é evocado ou utilizado em um processamento de um input pode ser influenciado pela motivação e pelas emoções, mas tanto a motivação como as emoções não modificarão o conteúdo sem que este esteja em um processamento. Por fim, os atos estão relacionados com as ações realizadas pelos indivíduos, ou seja, têm relação com os desejos, intenções e metas e são influenciados pela motivação.

Portanto, como defende Kreitler (2013), não há somente graus de motivação nas intenções de ações dos indivíduos, mas também níveis. Um deles é em relação aos atos cognitivos, como descrito anteriormente, bem como o que a autora chama de função de disposição motivacional, que aparece na entrada do input na mente (decodificação do input em fórmulas lógicas, como vimos anteriormente). Este input passa por uma espécie de "filtro" motivacional inconsciente ${ }^{3}$ (ou seja, não manifesto), que determina se o indivíduo está motivado para realizar aquele processamento. Acreditamos que este "filtro" não é exclusivo do ser humano e é um dos componentes que auxiliaram na evolução humana.

\footnotetext{
${ }^{3}$ Definiremos consciente aos elementos mentais que estão manifestos na mente, como por exemplo, o ato de levantar o braço para pegar algo, e inconscientes aos elementos mentais que não estão manifestos na realização de um ato, como por exemplo quais músculos são necessários para que eu levante o braço, e as ordens dadas pelo cérebro a esses músculos para que eu realize esta ação. (KREITLER, 2013; SPERBER; WILSON, 2001).
} 
A partir desta perspectiva podemos afirmar que a motivação é um componente mental que interfere nas ações que realizamos que são dependentes do efeito cognitivo e da atitude proposicional tomada pelo indivíduo após o processamento. Desta forma, a motivação deixa de ser vista como uma propriedade da aquisição, como Ellis (1994) defende, ou como uma propriedade social determinada pelas diferentes identidades dos sujeitos, como defende Norton (2015), mas toma um lugar de destaque na mente, colocada em igualdade com a cognição e a emoção. Assim, na perspectiva Kreitler (2013), a motivação é um conceito mental, que por meio do conhecimento enciclopédico, emoções, vivências e afetividade, afetará as ações sociais.

Logo, é possível evidenciarmos que são muitas as semelhanças entre a motivação e a relevância, como por exemplo, sua dependência do contexto e dos elementos idiossincráticos dos indivíduos, bem como seu conhecimento enciclopédico. A partir da visão de que a motivação é uma propriedade mental definida em graus, e que ela é tão importante quanto às emoções e a cognição, nos perguntamos: onde está a relevância? Segundo Sperber e Wilson (2001), a relevância é um elemento indispensável no processo cognitivo, portanto, ela faz parte da racionalidade humana.

Como descreve Kreitler (2013, p. 2), a motivação e a cognição não podem operar independentemente uma da outra. Assim, a autora defende que a motivação representa uma força de um organismo para um desejo/meta que leva a uma reação e a um comportamento. Essa reação, em termos da TR, pode ser descrita como o significado resultante do processamento, o efeito contextual alcançado que leva ao comportamento, ou seja, à atitude proposicional plena.

Desta forma, podemos dizer que o input, ao entrar na mente, não passa por apenas uma disposição de motivação inconsciente, mas também por uma expectativa possível de relevância. Além disso, a motivação é determinante para a realização do processamento inferencial, para que haja um efeito final no processamento. Do mesmo modo, é necessário que este efeito final seja relevante, para que ocorra a contextualização do novo conhecimento e a retroalimentação da motivação e da relevância, e a posterior ação, ou seja, a atitude proposicional. Logo, podemos dizer que a relevância e a motivação são dependentes uma da outra, mesmo que haja níveis de motivação que influenciam no processamento mental (nível inicial de uma 
disposição de motivação, nível de motivação intrínseca ou extrínseca, etc.). Estas questões são de grande importância para os estudiosos da aquisição (inclusive professores atuantes), estudiosos da linguagem e estudiosos da mente, bem como interessados no assunto, pois mostram que a mente não é formada somente pela cognição e seus componentes racionais, mas também pela motivação e pelas emoções. Por questões de tempo e espaço, esta discussão não será aprofundada nesta pesquisa, mas ficam aqui várias hipóteses interessantes para pesquisas futuras.

Assim, é evidente que, na hipótese de que a motivação é um componente mental e a relevância faz parte de outro componente mental, a cognição, existe uma relação intrínseca entre estas duas propriedades. Esta relação se dá à medida que quanto mais relevante a nova informação/evocação for, mais intrínseca se torna a motivação. Como vimos, quanto maior o grau de relevância, mais intrínseca será a motivação, ao passo que, quanto menor o grau de relevância, mais extrínseca será a motivação, podendo chegar a amotivação (em relação a um input).

Como tanto a motivação quanto a relevância são propriedades internas do ser humano, acreditamos que não há possibilidade de um input ser ao mesmo tempo motivante, mas não ser relevante. Isso se dá pelos diversos argumentos citados acima, bem como pela relação intrínseca entre a relevância e a motivação. Por fim, se o indivíduo não estiver motivado e não existir relevância (nem uma expectativa de relevância) ao input a ser processado, ele será descartado e o indivíduo não realizará a ação proposta. Na teoria de Deci e Ryan (2000), essa reação pode ser entendida como a amotivação. Utilizaremos este termo apenas como modo de ilustrar a não realização da ação pelo indivíduo, mas não que ele esteja somente desmotivado. Neste caso o novo input, seja ele qual for, não é motivante o bastante para passar pela disposição inconsciente de motivação, nem é relevante o bastante para que haja uma expectativa de relevância e este novo dado seja processado. Provavelmente a ação final do indivíduo será ignorar esse novo input, prestando atenção em outras coisas que lhe sejam mais relevantes.

Nesta hipótese, consideramos a relevância como resultado do processamento podendo, desta forma, manter ou alterar o grau de motivação de acordo com a relevância já formulada pela presunção de relevância e pelo processamento do input. 
Se considerarmos a relevância como uma expectativa, ou seja, a expectativa inicial de relevância antes do processamento em si, não teremos como afirmar com certeza nem o grau de relevância, nem o grau de motivação, visto que ao decorrer do processamento o grau de relevância pode ser diminuído ou aumentado. Além disso, como demonstramos acima, tanto a relevância como a motivação são dependentes do significado que o input tem. Se pensarmos na relevância como uma expectativa, como o processamento não se deu ainda efetivamente, não há significado. O mesmo ocorre com o contexto e a relação das idiossincrasias.

Entretanto, como já afirmamos as reações descritas de ser motivador e relevante ou não ser motivador e relevante são dinâmicas: o grau de relevância para um certo input pode mudar, não sendo estática esta condição. Logo, quanto maior o grau de relevância, mais intrínseca será a motivação. Isso explica o fato de, mesmo que o processamento de uma nova entrada ocasione um grande esforço, por este indivíduo estar intrinsecamente motivado ele compensará este esforço de processamento com um alto efeito e um grau elevado de relevância, que irá retroalimentar a motivação, mantendo-a intrínseca. Se assim o for, nós propomos que o grau de motivação do indivíduo é aumentado quando a meta a ser atingida tem algum grau de relevância. Portanto, quanto mais relevante uma nova entrada de dados/evocação for, maior grau intrínseco terá a motivação.

\section{A concepção social na relação motivação/relevância.}

Quando estudamos os aspectos culturais da linguagem, tendemos a desenvolver pesquisas de cunho social, desconsiderando outras propriedades do ser humano, como as cognitivas. Por sua vez, a motivação referente à aquisição de língua é comumente proposta por estudiosos que se embasam no campo social da linguagem. Gardner (1999) foi o primeiro autor a pesquisar a relação entre motivação e aquisição de línguas e, consequentemente, a incluir aspectos sociais como o self e aspectos culturais nas pesquisas de motivação em línguas adicionais. Os estudos posteriores sobre o tema também levaram em consideração o lado social da motivação como primordial para a aquisição. Assim, a relação cultural e social tornou-se importante, 
bem como as atitudes em relação à cultura alvo, às crenças, ideais e expectativas na identificação e pertencimento com a outra cultura/sociedade.

Gardner (1999) relacionou a motivação em aprender línguas com a cultura. De acordo com o autor, para facilitar a interiorização da língua-alvo, é preciso que o estudante tenha um sentimento de pertença na cultura-alvo, ou seja, uma sensação de parentesco e sentir-se membro de um grupo. Desta forma, as relações interpessoais auxiliam na integração da motivação com o "eu”, gerando com o tempo a motivação intrínseca.

Dörnyei (2002) define a motivação como as forças internas e externas das metas individuais do aprendiz, pela interação comportamental do aprendiz com a língua e o contexto situacional. Dörnyei reconhece as individualidades cognitivas dos estudantes como estilos cognitivos diferentes. A partir destes estilos cognitivos e do entorno social surgem as possíveis identidades do self, que agem como um reforço motivacional, por meio das "identidades imaginadas". O termo "identidades imaginadas" refere-se às figuras que o aluno cria em mundos possíveis, em que ele se imagina ao estudar a língua e as possíveis relações destas identidades com a cultura e a sociedade imaginada. Em relação a isso, Anderson (1991) postula o termo "comunidades imaginadas": comunidades da língua alvo criadas na mente do aluno, com as quais ele irá também ter (ou não) um reforço motivacional.

Nos estudos mais recentes de aquisição de línguas e motivação está a proposta de Norton (2015). Norton relaciona as identidades dos alunos e seu capital cultural (experiências) com as ideologias, nas quais estes alunos estão inseridos socialmente. A autora defende que a motivação sugerida por autores cognitivistas não cabe às necessidades identitárias dos alunos, que são mutáveis socialmente. Além disso, ela defende que o mundo social está em constante mudança, o que reforça as identidades complexas dos aprendizes. Assim, Norton propõe um aprimoramento da motivação, apresentando o conceito de investimento. Logo, o aluno não está motivado ou desmotivado para aprender uma língua, mas ele investe mais ou menos neste aprendizado, de acordo com sua identidade e a interação social.

Schmidt, Boraie, Kassabgy (1996) defendem que a motivação não pode ser cultural, pois as teorias de motivação passariam a ser etnocêntricas e os estudos seriam 
individualizados para cada país, sendo necessária a criação de uma teoria da motivação americana, uma teoria da motivação italiana, uma teoria da motivação alemã, e assim por diante. Portanto a motivação, para os autores, é universal e não cultural. Se pensarmos em termos de culturas, realmente será difícil relacionar motivação com as diversas culturas existentes. Acreditamos que se utilizarmos como base o conceito de comunidades de prática, será muito mais fácil a relação de uma socialização do indivíduo, de acordo com sua motivação. As comunidades de prática permitem que os âmbitos culturais não estejam relacionados com a cultura, mas com as diferenças culturais dentro de cada cultura, em suas comunidades. Logo, ao aprender uma língua é necessário estudar como as comunidades de interação social da língua alvo funcionam, tentando não cair nos estereótipos culturais criados.

Nesta perspectiva, por meio das referências consultadas, fica evidente que os aspectos socioculturais da linguagem são desconectados dos aspectos cognitivos, com o argumento de que o social e subjetivo é dinâmico e está em constante mudança, e o cognitivo é estático e rotular, assim como as definições de motivação propostas pela Psicologia. Desta forma, a aquisição de línguas levantada por esses estudiosos é vista como uma recepção de conhecimento, em que o aluno irá utilizar este conhecimento "recebido" em situações reais, de acordo com a sua dinâmica situacional de sujeito.

Porém, a motivação não é apenas uma definição entre extrínseco ou intrínseco, inerte e estático, mas uma propriedade mental que determina as ações do ser humano em relação ao mundo real. Esta relação se dá pelo contexto, que é dinâmico e reorganizado a cada momento. Logo, não há como considerar a motivação como uma propriedade da aquisição, como considera Ellis (1994), nem como peculiaridade cognitiva e, portanto, descartada por uma concepção social.

Defendemos que a motivação faz parte dos seres humanos como componente integrante da mente e que está em constante mudança, de acordo com as mudanças do contexto situacional e cognitivo. O contexto cognitivo é alimentado pelo contexto situacional, o que permite todas estas mudanças. Além disso, as emoções, crenças e estilos cognitivos permitem que as idiossincrasias façam parte das inferências e, portanto, das possíveis ações. Logo, todo contexto social é regido por um contexto cognitivo, assim como toda situação real vivenciada na língua será regida por meio 
das crenças que o aluno tem e seus conhecimentos enciclopédicos. Os conhecimentos enciclopédicos, as vivências e as crenças do ser humano são um reflexo das crenças da comunidade de prática que esse indivíduo está inserido.

Se assim o for, não há como dissociar cognição de socialização. Esta perspectiva também é partilhada por Damásio (2012), que defende que as construções biológicas dos indivíduos, ou seja, o ambiente cognitivo é construído por meio da interação social e das experiências, ao mesmo tempo em que os fatores cognitivos e afetivos determinam a socialização com os demais indivíduos da comunidade. Por conseguinte, não há como determinar uma teoria da motivação de cunho social e cultural sem levar em conta que os aspectos das diferentes comunidades de prática estão interiorizados na mente e são relacionados constantemente com as idiossincrasias dos indivíduos. Logo, fica clara a necessidade de uma teoria motivacional que leve em conta os dois aspectos, pois todo ser humano tem suas individualidades e é por meio delas que ele se comunicará e haverá a interação com o mundo social.

\section{Considerações finais}

A Pragmática tem estado presente em diversos campos de estudo atualmente, contribuindo para as pesquisas da comunicação e do uso da linguagem. Neste texto nos propusemos estudar as relações entre alguns aspectos pragmáticos da comunicação e da aquisição de línguas adicionais. Acreditamos que a motivação e a relevância são propriedades cognitivas necessárias para a aquisição de línguas adicionais, e que elas se relacionam de forma a contribuírem para o processamento de inputs da língua-alvo, bem como sua aquisição.

Com base no construto teórico levantado buscamos relacionar as duas propriedades, motivação e relevância. Identificamos que os dois elementos têm características muito parecidas e que são dependentes dos mesmos componentes. Enquanto a relevância determina o processo inferencial e seus efeitos e esforços, a motivação impulsiona e determina uma ação. A relevância e a motivação estão 
relacionadas com o significado do input, com o contexto situacional e cognitivo, as idiossincrasias dos indivíduos e seus conhecimentos enciclopédicos e experiências. As duas, relevância e motivação, são elementos dinâmicos, determinados em graus e que devem ser constantemente retroalimentadas. Além disso, são dependentes da relação efeito-esforço. Como são propriedades diferentes estão relacionadas com os constituintes elencados de formas diferentes, mas têm sua dependência de forma igual. Se trouxermos estas características para o processo de aquisição de línguas adicionais veremos que todas elas estão interligadas com este processo, e sanam muitas (se não todas) das necessidades para que haja a aquisição de línguas adicionais. Neste caso, podemos afirmar que a motivação e a relevância fazem parte da aquisição de línguas.

Em consequência, verificamos também que, mesmo que estas propriedades estejam relacionadas com o lado cognitivo da aprendizagem de língua, elas têm relação direta com o lado social. Pudemos afirmar que o ambiente e a socialização constroem as representações conceituais dos aprendizes, bem como estas representações, juntamente com o contexto mental (crenças, afetividades e emoção) e a motivação determinam qual será a atitude proposicional do aluno em relação ao input recebido e sua posterior ação, e esta ação originará algum efeito social que retornará como input ao aluno e assim sucessivamente, ampliando e remodelando o ambiente cognitivo do aprendiz, bem como estruturando sua vida e relações sociais.

Assim, evidenciamos que a relevância e a motivação são propriedades mentais que formam nosso ambiente cognitivo e permitem a aquisição de novos inputs, bem como conhecimentos sobre uma nova língua. Logo, estas duas propriedades devem ser levadas em conta na hora do professor de línguas preparar, selecionar e partilhar os conteúdos aos estudantes, pois todo esta organização auxiliará na aquisição dos mesmos. Da mesma maneira, é importante que o professor de línguas também tenha uma relação afetiva favorável à aquisição, buscando conhecer seus alunos e também o que lhes é relevante. Isso não garantirá a aquisição do conhecimento e da língua adicional, mas permitirá um melhor ambiente de aprendizagem, bem como de resultados mais significativos em seus objetivos pedagógicos. 
PERcursos Linguísticos • Vitória (ES) •v. 10 •n. 26 • 2020 • ISSN: 2236-2592 •

Dossiê: Linguagem, Comunicação e Cognição •

\section{Referências}

ANDERSON, B. Imagined communities: reflections on the origin and spread of nationalism. New York: Verso, 1991.

DAMÁSIO, A. R. O erro de Descartes: emoção, razão e o cérebro humano. 3 ed. São Paulo: Companhia das Letras, 2012.

DÖRNYEI, Z. The motivational basis of language learning tasks. In P. Robinson (Ed.). Individual differences and instructed language learning. Amsterdam: John Benjamins, 2002, p. 137-158. Disponível em: <https://docs.wixstatic.com/ugd/ba 734f_26eadac4fc584e37b7cdae0902a5e1bd.pdf?index=true>. Acesso em: 19 dez. 2016.

DÖRNYEI, Z. Researching motivation: From integrativeness to the ideal L2 self. In: Hunston S.; Oakey D. (Eds.), Introducing applied linguistics: Concepts and skills. London: Routledge, 2010, p.74 - 83. Disponível em: <http://www.zoltandornyei.co.uk/ uploads/2010-dornyei-routledge.pdf $>$. Acesso em: 19 dez. 2016.

ELLIS. R. The study of second language acquisition. New York: Oxford, 1994.

GARDNER, R. C. Correlation, Causation, Motivation, and Second Language Acquisition. 1999, p. 10 - 24. Disponível em: < https://pdfs.semanticscholar.org/9907/ 66883fb85e9ad3785dbd8e4886df477f5958.pdf>. Acesso em: 05 jan. 2017.

GARDNER, R. C. Gardner and Lambert (1959): Fifty Years and Counting. Ottawa: Canadian Association of Applied Linguistics, 2009. Disponível em: <http://publish.uwo.ca/ gardner/docs/CAALOttawa2009talkc.pdf>. Acesso em: 05 jan. 2017.

KREITLER, S. The Structure and Dynamics of Cognitive Orientation. In.: KREITLER, S. Cognition \& Motivation: forging an interdisciplinary perspective. New York: Cambridge University Press, 2013, p.32-61.

KRUGLANSKI, A. W.; SHEVELAND, A. Epistemic Motivations. In.: KREITLER, Shulamith. Cognition \& Motivation: forging an interdisciplinary perspective. New York: Cambridge University Press, 2013, p.15-31.

NORTON, B. Identity, Investment, and Faces of English Internationally. Chinese Journal of Applied Linguistics (Quarterly), v. 38, n. 4, 2015, p. 375 - 391. Disponível em: <http://faculty.educ.ubc.ca/norton/Norton\%20in\%20CJAL\%202015\%20publi shed.pdf>. Acesso em: 15 mai. 2016.

RYAN, R. M.; DECI, E. L. Intrinsic and Extrinsic Motivations: Classic Definitions an New Directions. Contemporary Educational Psychology 25, 2000, p. 
54 - 67. Disponível em: 〈https://mmrg.pbworks.com/f/Ryan,+Deci+00.pdf>. Acesso em: 12 jan. 2017.

SCHMIDT, R.; BORAIE, D.; KASSABGY, O. Foreign language motivation: Internal structure and external connections. In. Rebecca Oxford (Ed.), Language Learning Motivation: Pathways to the New Century. Honolulu: University of Hawai, 1996, p. 9 - 70. Disponível em: <http://nflrc.hawaii.edu/PDFs/SCHMIDT\%20Foreign\%20 language\%20motivation.pdf $>$. Acesso em: 08 jan. 2017.

SCHWARTZ, S. Motivação para ensinar e aprender: teoria e prática. Petrópolis: Vozes, 2014.

SPERBER, D; WILSON, D. Relevância: comunicação e Cognição. Trad. Helen Santos Alves. Lisboa: Fundação Calouste Gulbenkian, 2001. (Original em 1986).

SPERBER, D; WILSON, D. Teoria da Relevância. In: Linguagem em (Dis)curso. Org. Fábio José Rauen; Jane Rita Caetano da Silveira. v. 1, n. 1, Tubarão: Ed. Unisul, 2005 , p. $221-268$.

TAPIA, J. A. Motivar para el aprendizaje: teorias y estratégias. Barcelos: Edebe, 1997.

TAPIA, J. A.; FITA, E. C. A motivação em sala de aula: o que e, como se faz. Trad. Sandra Garcia. 11 ed. São Paulo: Edições Loyola, 2015. 